CLINICAL IMAGE

\title{
The 'Starry Sky' in Tuberculoma
}

\author{
Shinjan Patra ${ }^{1}$, Partha Pratim Chakraborty ${ }^{1}$, Gouranga Santra ${ }^{1}$, Sugata Narayan Biswas ${ }^{1}$, Kripasindhu \\ Gantait $^{\top}$
}

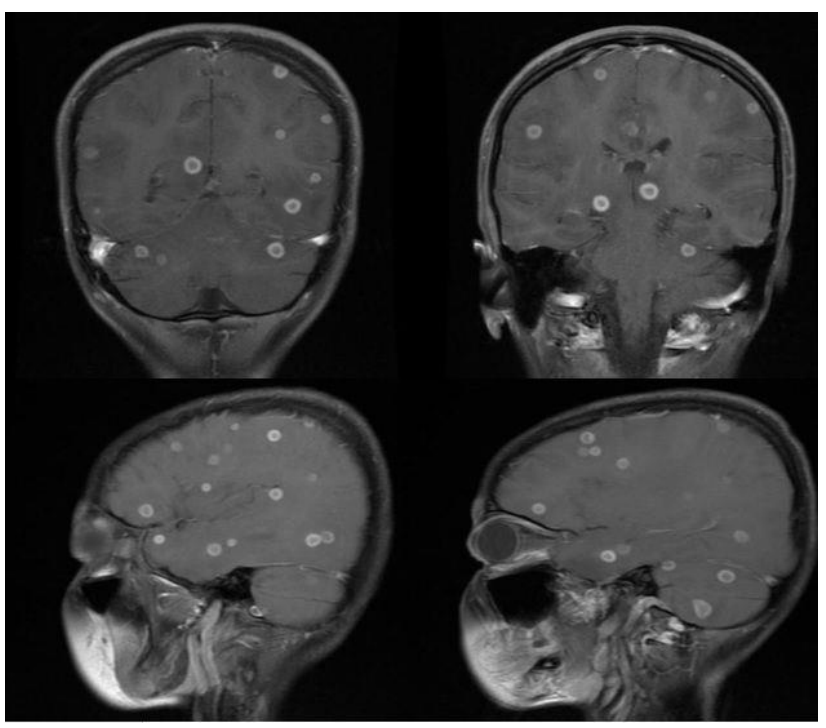

Figure 1. Gadolinium enhanced coronal (upper panel) \& saggital (lower panel) T1W images of MRI brain showing multiple ring enhancing lesions with thick rims appeared as 'Starry Sky'.

\section{CASE}

A 27 year old lady was admitted with high-grade fever, severe headache along with dry-cough and she was being treated for neurocysticercosis on basis of 'starry sky' pattern on her magnetic resonance imaging (MRI) of brain.

She was found to have hemorrhagic and exudative pleural effusion (Light's criteria) with lymphocytic pleocytosis, adenosine deaminase (ADA) value was $105.2 \mathrm{U} / \mathrm{L}$, cartridge based nucleic acid amplification test (CBNAAT) for tubercular bacilli from fluid came positive and Mantoux test was positive also. With a strong suspicion of tuberculosis the patient was put on anti-tubercular therapy along with anticonvulsants and oral steroid. Interestingly she showed remarkable permanent improvement.

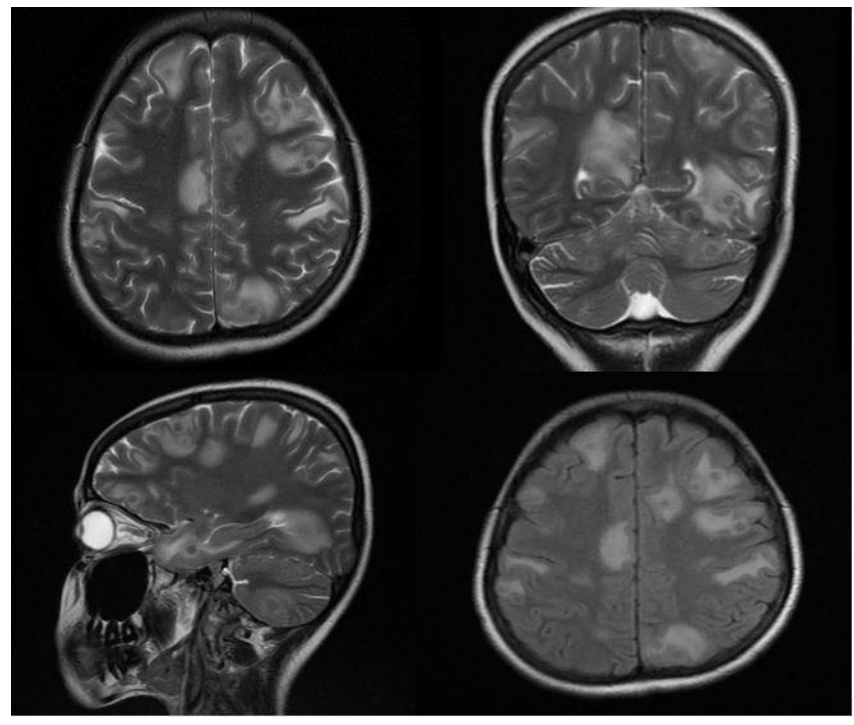

Figure 2. Axial coronal and saggital T2W and FLAIR (right inferior image) images of MRI brain showing multiple space occupying lesions with peri lesional edema.

Radiological appearances of tuberculoma closely mimic a number of conditions of which neurocysticercosis heads the list followed by brain abscesses, metastases, fungal granulomas. We performed another MRI brain which showed innumerable space occupying lesions with iso-intensity with grey matter in T1 weighted images and central hypointencity in T2 weighted images. This 'rim enhancing' lesions are characteristically thick rimmed, with same morphology and central speak of calcification, without mural nodule and having profuse surrounding edema in T2 flair images speak firmly in favor of tuberculoma. This 'starry sky' appearance is quite rare with a handful of cases in world literature as this appearance has traditionally been synonymous for neurocysticercosis. So we have to keep tuberculoma as an important differential of the

${ }^{1}$ Department of General Medicine, Midnapore Medical College and Hospital, Midnapore, West Bengal, India

Correspondence: Dr. Shinjan Patra, Department of General Medicine, Midnapore Medical College and Hospital, Midnapore,

West Bengal, India, E-mail: shinjan100@gmail.com

Received: 28 April 2016, Accepted: 22 November 2016

Copyright (C JMID / Journal of Microbiology and Infectious Diseases 2017, All rights reserved 
"starry sky" appearance in the developing countries and a thorough clinical examination is of utmost importance in every such case to avoid misdiagnosis and resultant fatal outcome.

\section{REFERENCES}

WHO annual report of Tuberculosis 2015; p-10-13

Ramamurthi B, Varadarajan MG. Diagnosis of tuberculomas of the brain: Clinical and radiological correlation. J. Neurosurg. 1961 Jan;18:1-7.

Gee GT, Bazan C 3rd, Jinkins, JR. Miliary tuberculosis involving the brain. MR findings. AJR Am J Roentgenol. 1992 Nov;159(5):1075-1076.

Gupta RK, Jena A., Sharma A, Guha DK, Khushu S, Gupta AK. MR imaging of intracranial tuberculomas. J Comput Assist Tomogr. 1988; 12(2):280-5.

Gupta RK, Jena A, Singh AK, Sharma A, Puri V, Gupta M. Role of Magnetic Resonance (MR) in the diagnosis and management of intracranial tuberculomas. Clin Radiol. 1990;41(2):120-7.

Van Dyk A. CT of intracranial tuberculomas with specific reference to the "target sign". Neuroradiology. 1988;30(4):329-36.

Haimes $A B$, Zimmerman RD, Morgello $S$, et al.MR imaging of brain abscess. AJNR Am J Neuroradiol.1989; 10:279-291 